\title{
Thin-layer Chromatographic Determination of L-Ascorbic, L-Dehydroascorbic and 2.3-Diketo-L-gulonic Acids in Animal Tissues, Blood and Urine
}

\author{
By Z. Zloch and E. GINTER
}

\author{
From the Research Institute of Human Nutrition, Bratislava (Director: Doc. Dr. A. Buckeo) \\ and Institute of Hygiene, Medical Faculty of Charles University, Pilsen (Head: Doc. Dr. F. Vaniček), Czechoslovakia
}

(Eingegangen am 5. Januar 1970)

A new method for the determination of ascorbic, dehydroascorbic and 2.3-diketogulonic acids in animal tissues, blood and urine is described. The material for analysis is homogenized in the presence of stannous chloride in trichloracetic acid and the extract is divided into three aliquots: in one part the ascorbic acid is converted into dehydroascorbic acid by oxidation with bromine water, in the second part the original content of dehydroascorbic and diketogulonic acids is stabilized by the addition of thiourea and in the third part dehydroascorbic acid is reduced to ascorbic acid by thioglycolic acid. Reaction with 2.4-dinitrophenylhydrazine produces a mixture of osazones, from which the bis-hydrazone of diketogulonic acid is isolated by thin-layer chromatography on Silicagel (solvent, ethyl acetate-chloroformacetic acid 50:50:5 v/v). The amount of bis-hydrazone is determined photometrically at $502 \mathrm{~nm}$ after dissolution in ethyl-acetate-toluene $(1: 3 \mathrm{v} / \mathrm{v})$. The content of ascorbic, dehydroascorbic and diketogulonic acids is calculated by comparison of the results from the three aliquots of the extract. The described method is more specific and more sensitive than the former colorimetric methods and is suitable for the isolation and evaluation of small amounts of ascorbic, dehydroascorbic and diketogulonic acids labelled with carbon ${ }^{14} \mathrm{C}$.

Eine neue Methode für die Bestimmung von Ascorbin-, Dehydroascorbin- und 2,3-Diketogulonsäure in tierischen Geweben, Blut und Harn wird beschrieben. Das Untersuchungsmaterial wird in Gegenwart von $\mathrm{SnCl}_{2}$ in Trichloressigsäure homogenisiert. Der Extrakt wird in 3 Teile geteilt: in einem Teil wird die Ascorbinsäure durch Oxydation mit Bromwasser in Dehydroascorbinsäure überführt, im zweiten Teil der ursprüngliche Gehalt an Dehydroascorbinsäure und Diketogulonsäure dürch Zugabe von Thioharnstoff stabilisiert und im dritten Teil Dehydroascorbinsäure mit Thioglykolsäure zu Ascorbinsäure reduziert. Reaktion mit 2,4-Dinitrophenylhydrazin ergibt ein Gemisch von Osazonen, von denen das Bishydrazon der Diketogulonsäure durch Dünnschichtchromatographie an Silikagel isoliert wird (Entwicklung mit Äthylacetat/Chloroform/Essigsäure 50:60:5 v/v). Das Bishydrazon wird nach Extraktion in Äthylacetat/Toluol (1:3 v/v) photometrisch bei $502 \mathrm{~nm}$ bestimmt. Der Gehalt an Ascorbin-, Dehydroascorbin- und Diketogulonsäure wird durch Vergleich der Ergebnisse aus den drei Teilen des Extraktes ermittelt. Die beschriebene Methode ist spezifischer und empfindlicher als ältere colorimetrische Methoden und geeignet für die Isolierung und Bestimmung geringer Mengen ${ }^{14} \mathrm{C}$-markierter Ascorbin-, Dehydroascorbin- und Diketogulonsäure.

The most commonly used method for the simultaneous estimation of the content of ascorbic acid and its metabolites in animal material is based on the reaction of the oxidized form of ascorbic acid and diketogulonic acid with 2.4-dinitrophenylhydrazine and the photometric evaluation of the resulting osazone dissolved in mineral acid (1). In the simultaneous estimation of all of these substances advantage is taken of the reduction of the dehydroascorbic acid to ascorbic acid, which does not react with the phenylhydrazine reagent. In the differential method according to RoE and coworkers (2), before the addition of dinitrophenylhydrazine two aliquots of the sample are subjected to the action of the oxidizing or reducing agent, changing the ascorbic acid to its oxidized form, and the dehydroascorbic acid to ascorbic acid. To the third part of the sample the reagent is added without prior chemical reaction and the content of the individual components is then calculated from the results of the photometric measurement on all aliquots of the sample.

A serious drawback of this method and partly even of its newer modifications is the unspecific action of dinitrophenylhydrazine, which reacts with other naturally occuring ketoacids, aldehydes, monosaccharides etc. and gives results that are too high according to the chemical treatment of the sample. Another drawback represents the difficulty with the usually low content of dehydroascorbic and diketogulonic acids in the animal tissues and blood, for which the colorimetric method is not sensitive enough.

The chromatographic isolation of the osazones of dehydroascorbic and diketogulonic acids on thin layers or on paper, which have already been used successfully on plant and animal material $(3,4)$, increases the specificity of the method and at the same time enables the treatment of greater volumes of extracts with a low concentration of the studied substances than in the method of direct colorimetry. Our method of independent estimation of ascorbic acid and its metabolits is based on the method of ROE and coworkers (2) which we have modified and linked to the isolation of the bis-2.4dinitrophenylhydrazone of diketogulonic acid on a thin layer of Silicagel. Its advantage is a greater specificity, the applicability of the analysis to material with a low content of the examined substances and the possibility of using it in the isolation and scintillometric evaluation of the metabolites of ascorbic acid, labelled with ${ }^{14} \mathrm{C}$.

\section{Method}

The precise estimation of the content of ascorbic, dehydroascorbic and diketogulonic acids is conditioned by the fact that the individually performed reactions, that differentiate between them, should be quantitative and that the undesired changes of the examined substances should be prevented. These requirements 
concern especially the reduction of the dehydroascorbic acid in one portion of the extract and the oxidation of the ascorbic acid in the other so that the content of diketogulonic acid should not change and there should no alteration in the protection of ascorbic acid by antioxidation in the original extract and in those parts of it, where its reaction with dinitrophenylhydrazine is to be prevented. The conditions for the quantitative estimation of all three substances were determined and verified by an analysis of a series of solutions of ascorbic acid, dehydroascorbic acid and of the barium salt of diketogulonic acid prepared according to KENYON and coworkers (5), used in concentrations appearing in biological material or added to the tissues to be analysed before homogenization.

The extract of the sample is divided into three parts. Reactions are carried out to gain a value for the total content of vitamin $C$ and diketogulonic acid as osazones, while the total content of the original dehydroascorbic and diketogulonic acids as well as the content of diketogulonic acid itself are determined on the other samples. The osazone of diketogulonic acid is isolated from the mixture of osazones of the interfering substances by thin-layer chromatography on Silicagel and after dissolution is evaluated photometrically. The content of the individual components is calculated by comparing the results from all three parts of the extract.

\section{Prevention of the oxidation of ascorbic acid}

During homogenization of the sample ascorbic acid is easily oxidized under the influence of oxýgen, oxyhaemoglobin and heavy metal ions. In the aliquots of the extracts, in which the reduction of dehydroascorbic acid is performed or where an unchanged content of dehydroascorbic and diketogulonic acids is maintained, the reoxidation of ascorbic acid may occur and thus raise the content of decomposition products to the detriment of ascorbic acid. Endeavouring to exclude the oxidative losses of ascorbic acid we have studied the effectiveness of different antioxidants. The best results were achieved with the combination of stannous chloride and thiourea. Stannous chloride is a reliable stabilizer of ascorbic acid during the homogenization of tissues

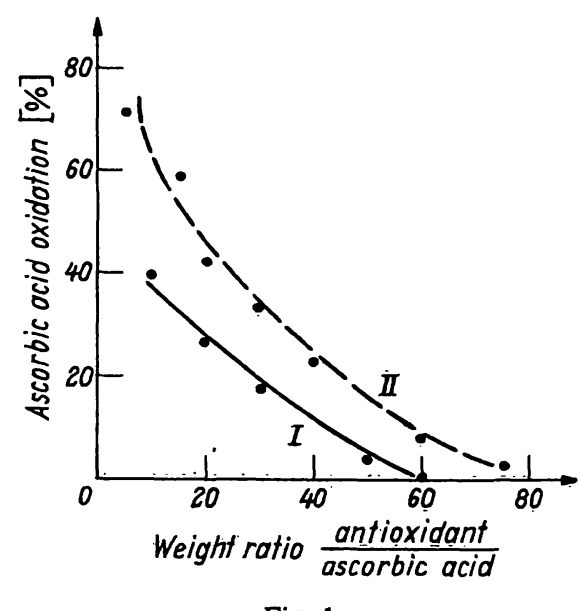

Fig. 1

Dependence of ascorbic acid oxidation on the weight ratio of antioxidant and ascorbic acid in $4 \%$ trichloracetic acid Antioxidant $I$ - stannous chloride Ii - thiourea

since in a 50-fold excess it prevents the oxidation of ascorbic acid (Fig. 1), i. e. at a concentration of $0.1 \mathrm{~g}$ per $100 \mathrm{ml}$ homogenate, whereas a 1000 -fold excess is required for the reduction of dehydroascorbic acid (Fig. 2). In comparison with stannous chloride, thiourea is approximately half as effective, but in higher concentrations it acts as a very effective reductant of dehydroascorbic acid. The addition of an exactly known amount of thiourea reliably. stabilizes the relative proportions of the single components.

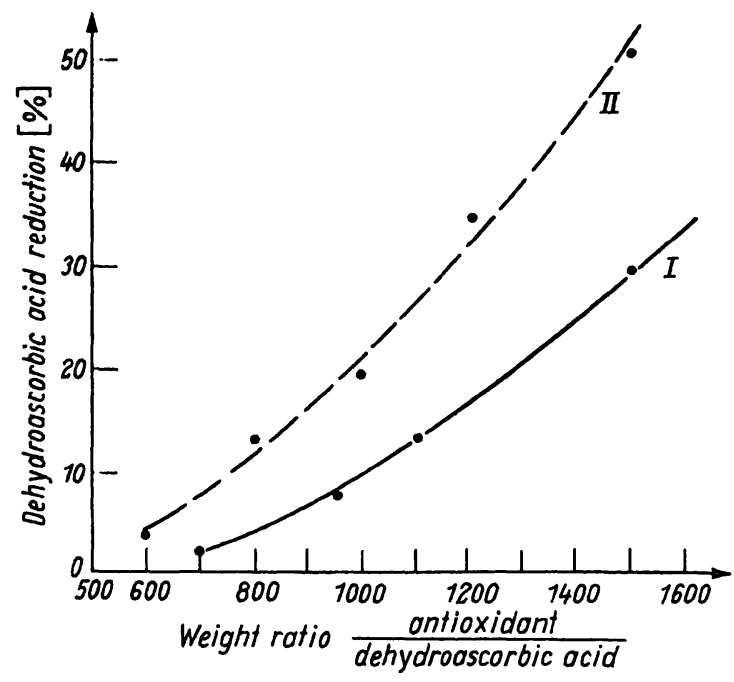

Fig. 2

Dependence of dehydroascorbic acid reduction on the weight ratio of antioxidant and dehydroascorbic acid in $4 \%$ trichloracetic acid Antioxidant I - stannous chloride II - thiourea

\section{Oxidation of ascorbic acid}

The oxidating agent was elected so as to achieve the quantitative conversion of ascorbic acid into dehydroascorbic acid and not to change the content of diketogulonic acid. In the presence of the concentrations of stannous chloride used norit was not effective enough and the use of 2.6-dichlorphenolindophenol or of benzoquinone produced osazones, which interfered in the chromatographic isolation of the bis - hydrazone of diketogulonic acid. The best results were obtained with bromine water, which oxidizes ascorbic acid effectively and quantitatively even in the presence of antioxidant and its excess may be removed by a stream of air.

\section{Reduction of deby'droascorbic acid}

In the method according to ROE and coworkers (2) the reduction of dehydroascorbic acid to ascorbic acid is effected by means of hydrogen sulphide at $\mathrm{pH}$ 3.5. This method is rather slow and may lead to a chemical change of diketogulonic acid (6). We have tried a great number of other recommended reducing agents, e. g. natrium dithionite, potassium pyrosulphite, cysteine and homocysteine, the last of which is the most suitable (7) for the reduction of dehydroascorbic acid at $\mathrm{pH} \mathrm{7.1,} \mathrm{but} \mathrm{under} \mathrm{the} \mathrm{given} \mathrm{conditions}$ according to our results it transforms about $30 \%$ of the diketogulonic acid to a derivate, which does not react with dinitrophenylhydrazine. Using solutions of dehydroascorbic acid and the barium salt of diketogulonic acid we have verified that thiogly-

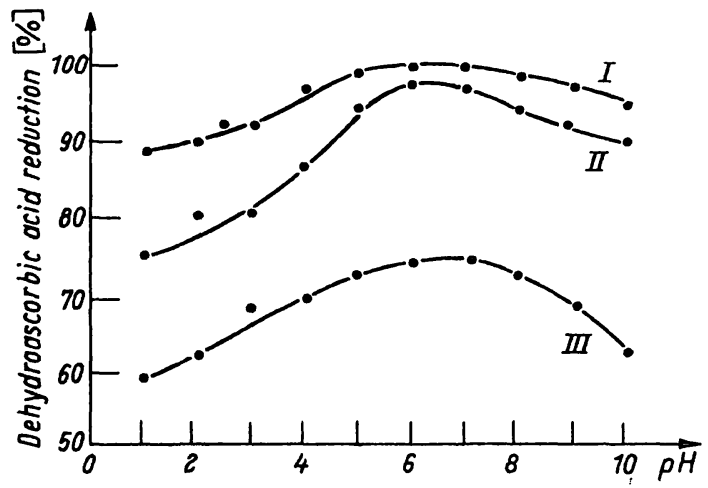

Fig. 3

Dependence of dehydroascorbic acid reduction by thioglycolic acid on the pH of the solution and the amount of thioglycolic acid Weight proportion thioglycollc acid : dehydroascorbic acid

$$
\begin{array}{r}
1-200: 1 \\
11=100: 1 \\
111-50: 1
\end{array}
$$


colic acid may be used and determined the optimal conditions for its reaction with dehydroascorbic acid (Fig. 3). At pH 6.0 and laboratory temperature the thioglycolic acid is as effective as homocysteine (in a 150 fold excess it reduces dehydroascorbic acid in $20 \mathrm{~min}$.), but it does not decrease the content of diketogulonic acid.

\section{Description of analytical method}

Reagents

$4 \%$ trichloracetic acid p. a. free from dissolved oxygen and cooled $+5^{\circ}$.

$10 \%$ trichloracetic acid p. a.

$25 \%$ solution of thiourea in $96 \%$ ethanol

$40 \%$ water solution of $\mathrm{K}_{3} \mathrm{PO}_{4}$ P. a.

$2 \%$ solution of $2.4-$ dinitrophenylhydrazine in $4 \mathrm{~N} \mathrm{HCl}$

$0.1 \mathrm{~N}$ sulphuric acid p. a.

bromine water (saturated)

cryst. stannous chloride p. a.

$80 \%$ water solution of thioglycolic acid - before use it is diluted in the ratio $1: 9$ with water

Silicagel $\mathrm{CH}$, mesh 5-40 $\mu \mathrm{m}$ (for TLC)

ethyl acetate - for chromatographic purposes it is shaken with $1 / 5$ of the volume of satured $\mathrm{Na}_{2} \mathrm{CO}_{3}$ solution and with a $1 / 5$ volume of saturated calcium chloride solution; the next day it is redistilled with cryst. calcium chloride

chloroform - this is shaken with water, than with concentrated sulpuric acid and redistilled

toluene - this is shaken with concentrated sulphuric acid, the turbid fraction is distilled away, metallic sodium is added and the mixture is redistilled

acetic acid p. a.

\section{Preparation of the sample extract}

Tissues and blood are taken immediately after killing the animal and at once treated or cooled to $-30^{\circ}$. The urine is conserved by addition $0.5 \mathrm{~m} l$ acetic acid to $10 \mathrm{~m} l$ of sample. The extracts are prepared by homogenization of $0.1-2 \mathrm{~g}$ of tissue or $5 \mathrm{ml}$ of blood and/or urine with $10-15 \mathrm{ml}$ of $4 \%$ trichloracetic acid and with $20-50 \mathrm{mg}$ of stannous chloride.

\section{Division of the extract}

1st. series of test-tubes-estimation of total content of vitamin $C$ and diketogulonic acid ... $1-2 \mathrm{~m} /$.

2nd. series of test-tubes-estimation of dehydroascorbic and diketogulonic acids . . . 3-4 ml.

3 rd. series of test-tubes-estimation of diketogulonic acid content $\ldots .5 \mathrm{~m} l$. Preparation of osazone of debydroascorbic and diketogulonic acids by
means of a differential method

Immediately after the division of the extract 1 drop of thiourea and $1 \mathrm{~m} l$ of dinitrophenylhydrazine solution are added to the second series of centrifugation test-tubes, which are then shaken and placed in the refrigerator.

The extract in the third series of test-tubes is neutralized by a known quantity of $\mathrm{K}_{3} \mathrm{PO}_{4}$ solution to $\mathrm{pH} 6.0$ and 1 drop of diluted thioglycolic acid is added. After stirring it is left at laboratory temperature for $20 \mathrm{~min}$. Then the solution is acidified with $2 \mathrm{ml}$ of $10 \%$ trichloracetic acid, and 2 drops of thiourea and $1 \mathrm{~m} l$ of dinitrophenylhydrazine solution are added.

While the reduction is taking place in the third series of test-tubes, the extracts in the first series of test-tubes are treated with bromine water (till to the occurrence of permanent yellow colour). The excess of bromine is removed by a stream of air and after the addition of $1 \mathrm{ml}$ dinitrophenylhydrazine the solution is stirred.

All three series of test-tubes are then brought to a temperature of about $37^{\circ}$ and kept at this temperature for $3 \mathrm{hrs}$.

\section{Isolation of osazone mixture}

At the end of the incubation time the reaction mixtures are quickly cooled in their test tubes in an ice bath and then centrifuged for $45 \mathrm{~min}$. at $2000 \mathrm{~g}$. The sediment contains the product from the coupling reaction of dehydroascorbic and diketogulonic acids with the dinitrophenylhydrazine, which has been identified as the bis-2.4-dinitrophenylhydrazone of diketogulonic acid (3) and further the unsoluble products of the reaction of dinitrophenylhydrazine with other natural components of biological material. The sediment is washed once with $0.1 \mathrm{~N}$ sulphuric acid and at least twice with distilled water and it is always centrifuged $(20 \mathrm{~min}$. at $2000 \mathrm{~g}$ ). The test-tubes are then placed in the desiccator and dried in vacuo over Silicagel overnight.

Chromatographic separation and photometric estimation of the osazone of diketogulonic acid

Exactly $50-100 \mu l$ of ethylacetate are added to the test-tubes containing the dried mixture of osazones. After dissolution exactly $20-60 \mu l$ of the solution are placed by means of a micropipet onto a $0.3 \mathrm{~mm}$ layer of Silicagel $\mathrm{CH}$, activated 1 hour at $110^{\circ}$. This is developed in the system ethyl acetate - chloroform acetic acid $(50: 60: 5 \mathrm{v} / \mathrm{v})(3)$. The osazone of diketogulonic acid formes a clear red and well separated spot of $R_{F} 0.60$, which is scarped down into the test-tubes after drying the chromatogram. The osazone is extracted with $3 \mathrm{ml}$ of a mixture of ethyl acetate and toluene $(1: 3 \mathrm{v} / \mathrm{v})$. The test-tubes are sealed and centrifuged for $5 \mathrm{~min}$. at $200 \mathrm{~g}$. The colour of the supernatant is at once measured on a spectrophotometer in a $2 \mathrm{~cm}$ cell at wave length $502 \mathrm{~nm}$. The solution of the osazone of diketogulonic acid may at the same time be used to measure the radioactivity by liquid scintillation counting.

\section{Calculation}

The amount of vitamin $C$ in the extract from the chromatogram is read from the calibration curve (in $\mu \mathrm{g}$ ). This value is used in the following formula to calculate the $\mathrm{mg}$ of vitamin $\mathrm{C}$ per $100 \mathrm{~g}$ of material:

$\mathrm{mg}$ vitamin $C$ per $100 \mathrm{~g}($ or $100 \mathrm{ml})=\frac{\mathrm{a} \cdot \mathrm{c}}{\mathrm{n} \cdot \mathrm{b} \cdot \mathrm{d}} \cdot 0.1 \mathrm{~A}$

where

$\mathrm{n}=$ amount of the sample ( $\mathrm{g}$ or $\mathrm{m} \mathrm{l}$ )

$\mathrm{a}=$ volume of the homogenate $(\mathrm{ml})$

$\mathrm{b}=$ volume of the extract taken for analysis $(\mathrm{m} l)$

$c=$ volume of ethyl acetate, used for the solution of the osazone mixture $(\mu l)$

$\mathrm{d}=$ volume of the solution of the osazone mixture, placed on the thin layer of Silicagel $(\mu l)$

$\mathrm{A}=$ amount of vitamin $\mathrm{C}$, read from the calibration curve $(\mu \mathrm{g})$.

The content of ascorbic, dehydroascorbic and diketogulonic acids is calculated from the values obtained from the three parts of the sample extract:

Content of ascorbic acid = difference between the values from the first (oxidized) and second series of test-tubes.

Content of debydroascorbic acid = difference between the values from the second and third (reduced) series of test-tubes.

Content of diketogulonic acid = values from the third series of test tubes.

To obtain the calibration curve a basal solution of ascorbic acid in $4 \%$ trichloracetic acid is prepared, oxidized by bromine water and diluted in a solution series of concentrations of $0.5-25 \mu \mathrm{g}$ dehydroascorbic acid per $1 \mathrm{~m} l$. The solutions are then treated in the same way as in the 1st. series of the sample extracts. Over the given concentration range the calibration curve is linear.

\section{Sensitivity of the method}

By the chromatographic method it is possible to estimate $0.5 \mu \mathrm{g}$ of material, which in a $3 \mathrm{~g}$ sample corresponds to a level of $0.05 \mathrm{mg}$ in $100 \mathrm{~g}$ of analyzed material. Qualitatively it is possible to detect on a chromatogram an amount smaller than $0.02 \mathrm{mg}$ of vitamin $\mathrm{C}$ in a $100 \mathrm{~g}$ sample. 
Tab. 1

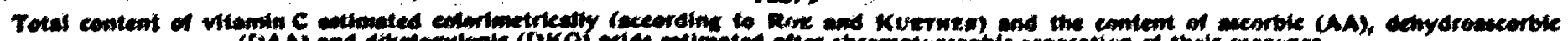

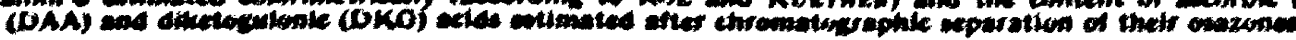

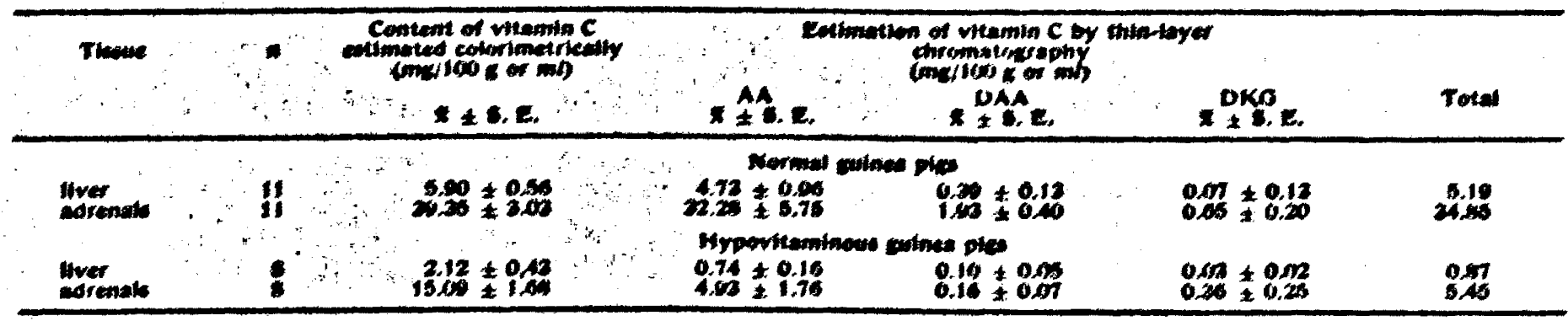

\section{Reaulte and diccuesion}

By the chromatographic separation of the osazone mixture it is possible to simplify the previous differen tation of the components of vitamin $C$ and at the same time the specificity of its estimation is higher. The improvement of the results achieved by the chromatographic isolation of the oxazone of diketogulonic acid were shown by the sesults of the comparative experiments, in which a part of the mixture of osazones, obrained by several modifications of the differential colorimetric method, was dissolved in ethyl acetate for a direct photometric measurement, and a part was separated on a thin-layes of Silieagel. The extinction values of the onzone mixture, obtained from the oxidized part of tissue or blood extracts were $50-100 \%$ higher than the values for the omzone of diketogulonie acid isolated from the same extract chromatographically. In the ehemically unchanged part of the extract these results were greater by $10-30 \%$ and in the reduced extract by 0-10\%. From these resules it follows, that interfering substances occur to an appreciable extent during the oxidation of the sample extract, whereas in the part of the extract subjected to the reducing agent their occurence is negligible. In the calculation of the content of ascorbic acid and its metabulites, extimated by the coloximetric method, the interfering substances are not quite eliminated and they cause falsely elevated values for the accorbic acid and to some extent for the dehydroascorbic acid.

The presence of the interfering factors is also manifested in the frequently used colorimetric method for the estimation of the total content of vitamin Caccording to Ror and Kuerwes (1), although the sorit used in this method partly adsorbs some intertering material (8). Table 1 shows the results of the estimation of vitamin $C$ content by this method and the sesults of a paxallel chromatographic extimation of accurbic acid and its metabolites.

In the analyzed tissues the sum of both forms of vitamin $C$ and diketogulonic acid obtained by the chromatographic method is $12-65 \%$ kower than the results of the colorimetric method; thewe differences are highest in tissues with a low eontent of vitamin $C$, in which the effect of interfering stobstances is greatest.

The ecproducibility of the chromatographic method was determined by a parallel analysis of the tissues alone and of tissues with the addition of $10 \mu \mathrm{g}$ of ascrorbic acid, dehydroascorbic acid and barium salt of diketrogulonic acid (chromatographically pure preparations). The secovery of the standard preparations of these substances ase quoted in Table 2.

Tab. 2

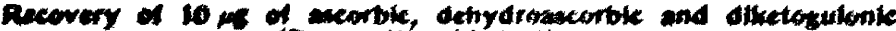

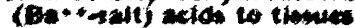

\begin{tabular}{|c|c|c|c|}
\hline Trume & $\begin{array}{c}\text { Aucorole } \\
\text { ncid } \\
\text { us }\end{array}$ & $\begin{array}{c}\text { Dethydramecorbic } \\
\text { msto }\end{array}$ & $\begin{array}{c}\text { Diketryulenic } \\
\text { acid } \\
\mu k\end{array}$ \\
\hline 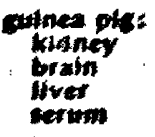 & $\begin{array}{l}10.05 \\
6.75 \\
9.40 \\
9.70\end{array}$ & $\begin{array}{l}9 / 4 \\
10 \% \\
10,70\end{array}$ & $\begin{array}{l}985 \\
1080 \\
10 \times 10\end{array}$ \\
\hline $\begin{array}{l}\text { rat: } \\
\text { tiver } \\
\text { spieten }\end{array}$ & 10 \&s & 10.20 & 9.50 \\
\hline
\end{tabular}

The mean exror determined for this method is not greater than $\pm 5 \%$; the extreme values found are $-12 \%$ and $+8.5 \%$. The relatively good xeproducibility of the method, its considerable vensitivity and its application to the isolation of metabulites of ascorbic acid for radionctivity measurements are some compensa tion for its sechnical difficulty and lengthiness. The proposed chromatographic modification may, however, be used as a coutine method, enabling to one perosn to perform at least 20 complete analywes of biological material in 1.5 working days.

\section{References}

1. Rox, J. H, and C. A. Kummex, J. biol. Cheminery 147, 399 (1943), - 2. Rox, J. H. M. B. Mrus, M. J. Orenemumo and

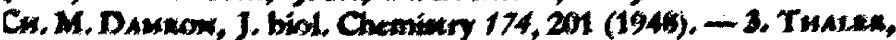
H. and M. Greoren, Mite, Lebencmicuelunuers, Bern 58, 473 (1967). 6. Zlock, Z, Mikecebim, Aat 753 (1969), - 5. Kewow, J. and
N. Muweo, 3. Chem. Sace. Lombrn 15 (1946), - 6. Pewwex, J. R. and 5. 5. Zutva, Birehem. J. 37, 403 (1943), - 7. Howits R. E., Biochem. J, 64, 263 (1956), - 8, Ron, J. H., An. N. Y. Acad. sci. 92, 277 (1961).

Zdenek Zkeh Plych, Ieningradsks on Cuchoulurakia 